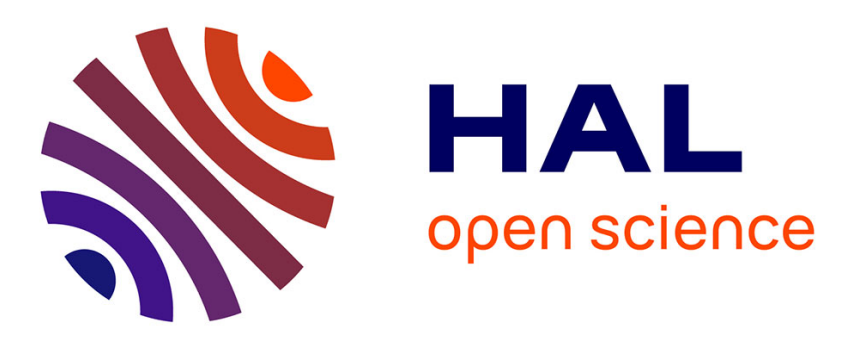

\title{
The Extended Resource Task Network: a new framework for the integrated scheduling of batch processes and CHP plants
}

Raphaële Théry Hétreux, Gilles Hetreux, Alain Haït, Mujtaba Agha, Jean-Marc Le Lann

\section{To cite this version:}

Raphaële Théry Hétreux, Gilles Hetreux, Alain Haït, Mujtaba Agha, Jean-Marc Le Lann. The Extended Resource Task Network: a new framework for the integrated scheduling of batch processes and CHP plants. International Journal of Production Research, 2011, pp.1. 10.1080/00207543.2010.545444 . hal-00728414

\section{HAL Id: hal-00728414 \\ https://hal.science/hal-00728414}

Submitted on 6 Sep 2012

HAL is a multi-disciplinary open access archive for the deposit and dissemination of scientific research documents, whether they are published or not. The documents may come from teaching and research institutions in France or abroad, or from public or private research centers.
L'archive ouverte pluridisciplinaire HAL, est destinée au dépôt et à la diffusion de documents scientifiques de niveau recherche, publiés ou non, émanant des établissements d'enseignement et de recherche français ou étrangers, des laboratoires publics ou privés. 


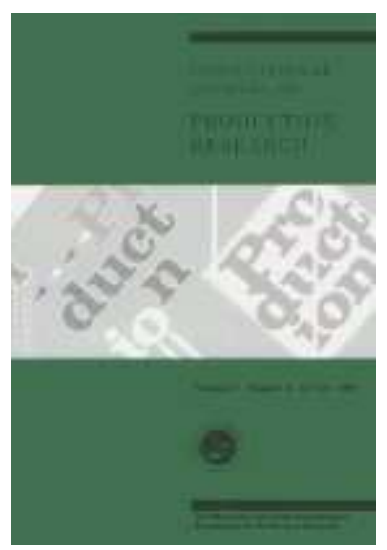

The Extended Resource Task Network: a new framework for the integrated scheduling of batch processes and CHP plants

\begin{tabular}{|c|c|}
\hline Journal: & International Journal of Production Research \\
\hline Manuscript ID: & TPRS-2010-IJPR-0363.R1 \\
\hline Manuscript Type: & Original Manuscript \\
\hline $\begin{array}{l}\text { Date Submitted by the } \\
\text { Author: }\end{array}$ & 28-Oct-2010 \\
\hline Complete List of Authors: & $\begin{array}{l}\text { THERY HETREUX, Raphaele; INPT ENSIACET } \\
\text { HETREUX, Gilles; INPT ENSIACET LGC } \\
\text { Haït, Alain; Institut Supérieur de I'Aéronautique et de I'Espace } \\
\text { AGHA, Mujtaba; INPT ENSIACET LGC } \\
\text { Le Lann, J; University of Toulouse, Laboratoire de Génie Chimique }\end{array}$ \\
\hline Keywords: & $\begin{array}{l}\text { BATCH SCHEDULING, ENERGY MANAGEMENT, MIXED INTEGER } \\
\text { LINEAR PROGRAMMING }\end{array}$ \\
\hline Keywords (user): & Utility Systems, ERTN \\
\hline
\end{tabular}

\section{SCHOLARONE ${ }^{m}$ Manuscripts}




\title{
The Extended Resource Task Network: a framework for the combined scheduling of batch processes and CHP plants
}

\author{
R. Théry ${ }^{\mathrm{a}}$, G. Hétreux ${ }^{\mathrm{a}}$ M.H. Agha ${ }^{\mathrm{a}}$, A. Haït ${ }^{\mathrm{b}}$, J.M. Le Lann ${ }^{\mathrm{a}}$ \\ ${ }^{a}$ Université de Toulouse, Laboratoire de Génie Chimique, ENSIACET-INPT, 4 allée \\ Emile Monso BP 4436231342 Toulouse Cedex 4. \\ ${ }^{b}$ Université de Toulouse, Institut Supérieur de l'Aéronautique et de L'Espace, 10 av. \\ E. Belin, 31005 Toulouse Cedex 4.
}

\begin{abstract}
The issue of energy has emerged as one of the greatest challenges facing mankind. In an industrial perspective, the development of site utility systems (generally Combined Heat and Power (CHP) systems) for the generation and management of utilities provides a great potential source for energy savings. However, in most industrial sites, a master/slave relationship usually governs this kind of system and limits the potential operating capacity of $C H P$. To improve the decision-making process, Agha et al (2010) have proposed an integrated approach that carries out simultaneous and consistent scheduling of batch production plants and site utility systems. The modelling of the problem relies on a Mixed Integer Linear Programming (MILP) formulation. Nevertheless, although it is a powerful mathematical tool, it still remains difficult to use for non-expert engineers. In this framework, a graphical formalism based on existing representations $(S T N, R T N)$ has been developed: the Extended Resource Task Network (ERTN). Combined with an efficient and generic MILP formulation, it permits various kinds of industrial problems, including production and consumption of utility flows to be modelled homogenously. This paper focuses on the semantic elements of the ERTN formalism and illustrates their use through representative examples.
\end{abstract}

Keywords: Batch scheduling, Energy Management, Mixed Integer Linear Programming (MILP), Utility system, Extended Resource Task Network (ERTN)

\section{Introduction}

The outlook on energy utilization has gone through a drastic change during the last few decades. Nowadays, contemplation on the provision and consumption of energy has greatly increased. This reflection has been brought about by a number of factors such as dwindling reserves of conventional energy sources, fluctuating energy prices, unavailability of alternative energy sources and new ecological realities about climate change. The search is on to find alternative energy sources that will replace fossil fuels as the primary source of energy. The goal is to find an energy source that is not only environmentally friendly but both economically viable and sociably acceptable. However, in the short term, fossil fuels will remain the main source of energy. Thus, pending the development of alternative energy sources, efforts must be made to promote methodologies for a more rational use of energy in all areas of human life. Initiatives like cleaner production (Kjaerheim, 2005) and zero-emissions (Kuehr, 2006) are important approaches in this regard. Moreover, recently in France, the conclusion drawn by the working group, "Lutter contre les changements climatiques et maîtriser l'énergie" ("Fight against climate change and control of energy"), gathered at the recent Grenelle de l'environnement (2009) is that, "beyond the specific 
actions to improve energy efficiency in the Building and Transport sector, there is a source of savings in other sectors which represent $43 \%$ of total energy consumption". In regards to the industrial sector (which accounts for $21 \%$ of final energy consumption and $20 \%$ of emissions of greenhouse gases), the working group recognized that significant efforts had already been made in this sector but pointed out that further progress was still required. The mode of production and management of utilities provide a great potential source for energy savings in the industrial sector as a whole but most particularly in the process industry. In this regard, the working group concluded that "approximately one third of the energy consumption of industrial (or final energy 11Mtep) comes from processes called "utility" (steam, hot air, heaters, electricity, etc.). The margins for improving the effectiveness of these processes exist. The dissemination and implementation of best practices can save up to 2 Mtep without requiring technological breakthroughs." One of the mechanisms identified by the working group to reduce energy consumption and greenhouse gas emissions is "the establishment of more efficient means of using process utilities" within production units. Combined Heat and Power (CHP) based on onsite utility systems can make useful contributions in this regard, especially in the case of industrial units that have high-energy needs.

Nevertheless, to maximize the potential of the onsite $C H P$ systems, it is imperative to coordinate the operation of both producing and consuming units. However, a "master/slave" relationship is traditionally encountered in industrial sites. In these decision systems, the emphasis is placed solely on production (manufacturing unit) and the utility system is treated as a subsidiary unit. As a consequence, the model used to solve production-scheduling problems generally considers utilities as a simple cumulative and renewable resource available in a fixed amount over time. How this resource is made available is absolutely not taken into account and the operation of the utility unit is completely ignored. In order to manage the utilization of utilities more rigorously, we have proposed an approach in a recent study (Agha et al., 2009 and Agha et al., 2010), which simultaneously carries out task scheduling of manufacturing units and operational planning of utility systems. In this framework, a mathematical model has been established where both units have equal importance and are uniformly modelled. As hoped, the analysis of several scenarios has demonstrated that this approach (called integrated approach) leads to a better coordination between the manufacturing unit and site utility system, a significant reduction in primary energy consumption, an increased use of cogeneration in the industrial site and a smoothing of steam curves. As a result, increases in productivity and reduced emissions of harmful gases have also been achieved.

Although it is a powerful modelling means, mathematical programming remains a rather technical tool that requires a certain expertise not always grasped by the 
practicing engineer. Thus, to facilitate the dissemination of these decision support tools, it seems appropriate to propose a generic mathematical formulation that can model a complete site (production unit and utility systems in a homogeneous manner. Then, this model is set using a well-defined graphical formalism (with semantics and rules) closer to the level of abstraction commonly handled by the process engineer. In that context, the objective of this paper is to describe:

- on the one hand, the Extended Resource Task Network (ERTN) formalism which proposes a unified framework for the description of a variety of process scheduling problems under energy constraints.

- on the other hand, one of the Mixed Integer Linear Programming (MILP) model associated with this graphical representation to solve the scheduling problem.

The remainder of the paper is organized as follows: the next section describes the general and specific characteristics of the industrial sites considered in this study and the existing frameworks used for modeling the site recipe. Then, section 3 introduces the semantic elements of the ERTN graphical representation. Section 4 inventories the constraints that can automatically be generated from a given set of the ERTN semantic elements. Finally, section 5 illustrates the use of the ERTN graphical formalism through a significant example.

\section{Scheduling problem and tools considered}

This section briefly highlights the specific features of industrial sites considered in this work, notably composed of a production plant and a site utility system.

\subsection{Characteristics of production plants and site utility systems}

\subsubsection{General features}

The addressed processes are multi-purpose batch or semi-continuous plant. In this kind of plant, each product follows a specific sequence of operations and is produced using different processing equipment that requires sharing. These general network processes correspond to the more general case in which batches can merge and/or split. This feature induces that material balances must be taken into account explicitly. Concerning the site utility system, a Combined Heat and Power (CHP) system is considered. Consequently, the corresponding scheduling model has to incorporate several general characteristics that include:

- disjunctive and cumulative resources constraints,

- various storage and transfer policies, 
- batch and continuous production modes,

- fixed and/or dependent processing times (depending on batch size),

- mixing and splitting of batches, inducing variable batch size along the production..

\subsubsection{Specificities of the considered cumulative resources}

In an industrial unit, the cumulative resources are generally subdivided into material resources and utility resources (figure 1). Nevertheless, some resources can be classified into both categories, according to the context of their use.

A classical example of this particular case are water derivative resources. Indeed, they are treated as material resources for the processing tasks executed to transform water from one phase to another. However, these water derivative resources are also carriers of energy and fulfill the utility requirements of processing tasks performed in the production plant. In this case, the water derivative resources act as utility resources. Obviously, these two situations have to be distinguished. Indeed, according to the nature of the cumulative resources, the consumed or produced quantities can either be governed by a mass balance equation (conservative) or be evaluated by a simple relationship (not conservative). For example, a material balance is needed to manage the inflows and outflows of a production operation. In contrast, the amount of utility required for this production operation can be assessed by a relation of consumption depending on the amount of treated material for example.

Another particular point is that numerous scheduling models assume that cumulative resources are supplied by independent external sources in limited and known quantities. A general assumption is that the resources are either renewable (constant level over the time horizon) or non-renewable (only consumed over the time horizon). However, this can be a very restrictive assumption in some cases. The production of utilities by a site utility system is a typical example. In this case, the utilities are often generated in limited but variable quantities. Moreover, the available amount of each utility can be interdependent with the generation of other utilities if a Combined Heat and Power (CHP) system is used. To properly evaluate the amount of each utility available at any given time, the unique solution is to take into account the operational constraints of the CHP plant.

\subsection{A graphical modelling framework}

Among the available CAPE tools (Computer Aided Process Engineering), process engineers are showing a growing interest in scheduling methods based on MILP formulation in order to carry out various performance analyses such as system 
productivity, time cycle, production costs or energy efficiency of a unit. During the development of a new process, these tools are used to perform mass and energy balances, equipment sizing, utilities needs assessment, estimation of time cycle or cost analysis. They provide the opportunity for users to experiment with different configurations on a "virtual" plant and can significantly reduce design variance, which is often costly. In operational terms, having a simplified but reliable model improves understanding of the whole process of interactions by the practicing operators. Indeed, they can promptly achieve off-line "What-if" or sensitivity analysis, extremely useful to managers in their daily work for assessing the impact of critical parameters on key indicators. For example, the impact of an increased order size (which affects the duration of tasks depending on the batch size) on the time cycle and on the number of batches can be estimated in a few minutes.

Nevertheless, the implementation and the tuning of a MILP model can become rather technical and complex in some cases. Thus, the support of a graphical representation can be very helpful for the modelling of the production system. Indeed, provided that the semantic of the formalism is sufficiently general, it allows the user to describe a problem in a simple and intuitive way while ignoring the mathematical model useful to its resolution. Another advantage of a well-defined graphical formalism is the ability to unambiguously model a problem by adding specific construction rules. It reduces (but it does not avoid) potential modelling mistakes and users can spend more time analysing the system rather than developing the model.

Obviously, the expressive quality of formalism is judged by its aptitude to summarize all the information necessary to the mathematical model, using a single graph. In this context, State Task Network (STN) proposed by Kondili et al. (1993) is a first step towards developing a universal representation for a batch plant. This general graphical framework is also used to develop a mathematical formulation applicable to a wide panel of batch plants. Later, Pantelides (1994) proposed the Resource Task Network $(R T N)$ formalism, which is an extension of the STN. In fact, RTN contains more information about processing equipment and their connectivity, an aspect which is not explicitly shown in STN. Moreover, a specific mathematical model has been proposed. Based upon the major concept of STN and RTN formalism, Agha (2010) have introduced new semantic elements and the resulting framework is called an Extended Resource Task Network (ERTN). It exploits the strength of the existing formalisms and, among other functions, it enables an explicit handling of cumulative resources (such as utilities for example) in batch production scheduling. Moreover, a specific mathematical model (presented in section 4) is associated with the ERTN framework.

\subsection{Modelling of recipes}


'Recipe' is an entity comprising the minimum set of information that clearly defines all the requirements for the manufacturing of a specific product. It describes the formulation (set of chemical substance and proportions), the procedure (set of physical steps required to make the product) and the required equipment. In the case of processes consisting of a large amount of processing equipment or elaborated manufacturing routines, the recipe can quickly become very complex. To address this complexity, the standard ISA/SP88 (www.isa.org) proposes a hierarchical model of the recipe (figure 2). Several levels of decisions have been identified in order to describe the content of recipes in an appropriate granularity:

- Generic (or general) recipe specifies the method of manufacturing the finished product. It contains the details about the materials (raw materials and intermediate products), proportions, operating parameters, etc. However, no details about the equipment used in the production process are provided.

- Site recipe site is an instantiation of the generic recipe in which the details about the production site are identified. This essentially involves clear definitions of the characteristics of the processing equipment (capacity, energy consumption, etc) along with the general topology of the process.

- Master recipe is a further instantiation, that of the site recipe, which sets the type and amount of finished product(s) to be produced in a given operational horizon. It therefore clarifies the production orders to be achieved. This level of recipe makes use of scheduling, which calculates the number and size of each batch as well as the passage sequence of these batches on equipment.

- Control recipe is applied to a particular batch or lot and describes the implementation of each task in detail. It is implemented at the supervision level.

In our case, the ERTN formalism permits the procedure associated with the site recipe to be modelled. It is constructed from the procedure of the generic recipe and the topology of the site (the production unit and CHP plant equipment) chosen to implement this recipe. The treatment of the resulting procedure and the production plan (list of production orders which defines the required amounts, timings and quantities of product) gives rise to the master recipe, depicted on a Gantt chart.

\section{Semantic elements of the $E R T N$ graphical formalism}

The ERTN graphical formalism has been implemented to unambiguously model the main features encountered in industrial processes such as material and energy flows (ratio of inlet and outlet flows, recycling, separation and mixing of batches), production procedures (precedence constraints) and resource constraints (topology of 
the unit, device capacity, fixed or variable operating time, shared and multimodal devices, etc.). Listed in table 1, the purpose of the following subsections is to precisely describe the semantic elements of the ERTN formalism.

\subsection{Task nodes}

A task node represents a processing operation that consumes and/or produces a specific set of resources. However, two kinds of operations have to be distinguished in a process: continuous operations, characterized by a flow rate between $R^{\min }$ et $R^{\max }$ and, discontinuous operations, characterized by a batch size comprising $B^{\min }$ and $B^{\max }$. Moreover, the duration of a continuous task $k$ is supposed to be fixed to $p f_{k}$ while the processing time of batch task $k$ is the contribution of $p f_{k}+p v_{k} \cdot B_{k, t}$ where $B_{k, t}$ is a variable equal to the batch size of task $k$. The graphical representation associated to each task node is shown in figure 3.

However, the duration of the residence time in these two kinds of operations are generally very different. Indeed, for a continuous operation, the residence time is often short, even negligible. Consequently, we can consider the processed material to be "immediately" available as soon as the steady state is reached. Instead, in a batch operation, the processed material becomes available only at the end of the operation. To take into account this difference in behaviour, a parameter defined as 'delivery time' is added. The delivery time $d d_{k}$ is a parameter that expresses the elapsed time between the arrival of a feed stream and the delivery of an output stream. Thus, in a "pure" batch task, $d d_{k}$ is implicitly equal to the processing time while $d d_{k}$ is implicitly equal to 0 in a "pure" continuous task.

\subsection{Cumulative resource nodes}

The cumulative resource node represents a resource that, at a given time, can be shared by multiple processing tasks. So, it is used to represent resources such as material state or utilities (figure 4.a). The material resources are raw materials, intermediate and finished products that are consumed or produced during the processing operation. Analogously, utility resources represent both primary and derivative utilities. The primary utilities represent, amongst others, resources like fossil fuel, electricity, water... The derivative utilities are resources obtained by processing a primary utility (for example, ambient water derived from steam at different pressures, hot water, cold water, etc.). The initial amount of resource, the capacity (if necessary) and the storage (UIS: Unlimited Intermediate Storage, FIS: Finite Intermediate storage, NIS: No Intermediate Storage) and transfer (ZW: ZeroWait) policies are the parameters associated with this kind of node. 


\subsection{Disjunctive resource nodes}

The disjunctive resource node (figure 4.b) represents a resource that, at a given time can be used by a single processing task at most. The disjunctive resources are generally processing equipment and manpower.

\subsection{State resource nodes}

The state resource node represents a state of an operation or device. Indeed, some complex devices can have different operating states. In particular, it may be necessary to follow a predetermined sequence of intermediate states before reaching a particular mode (often nominal mode). In this case, the unit is called multi-modal and the state resource node can be used to manage the transitions between modes (figure 4.c). This resource is consumed when the associated task is executed and delivered as soon as it ends. Like cumulative resource nodes, three parameters are associated with this node: the initial state (value equal to 0 for all nodes except that corresponding to the current state of the device which is 1), the capacity (here, always equal to 1) and the transfer policy.

\subsection{Disjunctive resource arc: "use" relationship}

The disjunctive resource arc establishes a "use" relationship between a disjunctive resource and a processing operation. It indicates that the disjunctive resource can perform the pointed processing operation. As a result, a task is defined as the couple (operation and disjunctive resource). This infers that the same operation performed on $n$ different devices is represented by $n$ tasks. Conversely, a device that is the source of $m$ disjunctive arcs graphically indicates that this device can perform $m$ different tasks (figure 5).

\subsection{Fixed and free flow arc}

The flow arc models any flow governed by a conservative mass balance equation. In this case, each input or output cumulative resource concerned by this relationship has to be linked to the processing task by such an arc. The proportion of each cumulative resource consumed or produced by a task can be either a parameter (fixed value located above the arc) or a variable of the problem (indicated by an arrow across the arc). Consequently, two kinds of flow arcs have been defined (figure 6): the fixed flow arcs where the fixed proportion is indicated on the arc and the free flow arcs identified by an arrow across the arc. Nevertheless, whatever the nature of the arc, the 
sum of the proportions carried by the input arcs of a task node must always be equal to 1 . This property must also be checked for output arcs.

\subsection{Consumption arc and Production arc}

In contrast to previous arcs, these arcs model any flow not governed by a conservative balance equation. In this case, each consumed or produced cumulative resource has to be linked to the processing task by such an arc. Two parameters characterize this relationship: in the case of a consumption, the parameter $u f_{k, r}^{c o n s}$ permits to represent the fixed quantity of resource $r$ consumed whereas $u v_{k, r}^{\text {cons }}$ represents the variable proportion of resource $r$ consumed with respect to the batch size performed by the task $k$ (figure 7.a). In the case of a production arc, the parameter $u f_{k, r}^{\text {prod }}$ and $u v_{k, r}^{\text {prod }}$ permit to define the amount of resource $r$ produced by task $k$ (figure 7.b).

It is important to note that the duality of certain resources (see section 2.1.2) induces that flow arcs and consumption/production arcs can appear simultaneously at a cumulative resource node. In the case of a water derivative resource for example, the use of different arcs clarifies when the resource acts as a material resource and also when it acts as a utility resource.

\subsection{Transition arc}

These specific arcs link a state resource node and a task node. The resulting sequence of states can be cyclic (figure 8.a) or not (figure 8.b). The current state of a device is determined by setting the parameter $S O$ of the corresponding node to 1 , the others being set to 0 . Indeed, this resource is governed by a conservative equation (but does not appear in the material balances) and cannot be assimilated to either a disjunctive resource, or a cumulative resource. Thus, in such a structure, a task can be executed only if it recovers a resource (integer) from the input state resource node. This resource is then released to the output state resource node at the end of the task. Finally, tasks belonging to the same sequence must be connected to the disjunctive resource node with a use arc, since a disjunctive resource can only be in one state at any given time.

\section{Mathematical model}

During the last few decades, the advances in computational power have made mathematical programming extremely popular. Several excellent reviews (Méndez et 
al. [2006], Floudas \& Lin [2004], Kallrath [2002] and Burkard R.E \& Hatzl J., [2005]) clearly point out that mixed integer linear programming (MILP) has been widely used for solving the batch process scheduling problem. In this framework, various formulations of the problem are proposed in the literature. Globally, we can distinguish MILP models based on discrete time formulation (such as Global time intervals) or based on continuous time formulation (such as Global time points, Unitspecific time event, Time slots, Unit-specific immediate precedence, Immediate precedence, General precedence, etc). Moreover, some authors have also proposed $M I L P$ models that incorporate utility aspects but the formulation is often quite specific to the addressed problem (Behdani et al. [2007], Zhang et al. [2005]). Instead, the main feature of the ERTN formalism lies in its generic nature, which allows for the development of direct correspondence between the semantic elements of the graphical representation and the mathematical constraints. Nevertheless, several formulations can be attached to this graphical formalism. Given this goal, any model allowing the simultaneous determination of the starting date and the batch-size of each task is a candidate, providing that a satisfactory solution is obtained in a reasonable time. In this article, only a discrete time MILP model is presented (figure 9), based on an extension of the Global time intervals formulation. Note that a continuous time MILP formulation has also been partially attached to the ERTN formalism in Hétreux et al., [2010].

\subsection{Allocation constraints}

Each structure including a disjunctive resource arc (figure 5) leads to the formulation of an allocation constraint. At a given time period $t$, a disjunctive resource $r\left(r \in R^{D}\right)$ such as processing equipment can, at most, initiate one task $k\left(k \in K_{r}\right)$. Then, this resource cannot execute another task $l\left(l \in K_{r}\right)$ during periods $t^{\prime}=t-p_{l}+l$ till $t^{\prime}=t+$ $\left.p_{k}-1\right)$. Equations (1) take into account full backward aggregation.

$$
\sum_{k \in K_{r} t^{\prime}=t-p_{k}+1} \sum_{\substack{t>0 \\ \text { s.t. }}}^{t} W_{k} \leq 1 \quad \forall r \in R^{D}, \forall t \in 1, \ldots, T
$$

Where $W_{k, t}=1$, if the task $k$ is launched at start of period $t$ and $W_{k, t}=0$ otherwise and $p_{k}$ defines the duration of the task $k$.

\subsection{Capacity constraint}

Cumulative resource node (figure 4.a) and state resource node (figure 4.c) are attached to a capacity limitation constraint represented by equations (2). It states that 
the amount $R_{r, t}$ of resource $r$ stored in period $t$ should never exceed its maximum storage capacity $C_{r}^{\max }$ :

$$
0 \leq R_{r, t} \leq C_{r}^{\max } \quad \forall r \in R^{C} \cup R^{S}, \forall t \in 1, . ., T
$$

\subsection{Batch size constraints}

Equation (3) limits the batch size (resp. flow rate) $B_{k, t}$ that can be undertaken by the batch task $k \in K^{B}$ (resp. continuous task $k \in K^{C}$ ) at time interval $t$. The batch size (resp. flow rate) $B_{k, t}$ is bound by the maximum $V_{k}^{\max }$ and minimum $v_{k}^{\min }$ values displayed on the task node :

$$
W_{k, t} V_{k}^{\min } \leq B_{k, t} \leq W_{k, t} V_{k}^{\max } \quad \forall k \in K, \forall t \in 1, \ldots, T
$$

\subsection{Cumulative resource mass balances}

As highlighted in section 2.1.2, a cumulative resource node can act simultaneously as a utility resource and material resource. So, it not only provides the material for a transformation process (acting as a material resource through the term $O_{r, k, t}$ and $I_{r, k, t}$ ) but can also fulfill the utility demands of a processing task (acting as a utility resource through the terms $U O_{r, k, t}$ and $U I_{r, k}$ ). Moreover, this node can receive resource from external sources (term $I n_{r, t}$ ) and can provide resource to external consumers (term $\left.O u t_{r, t}\right)$. As illustrated in figure 10, the mass balance around a resource node is captured in the graphical representation by the use of different arcs coming into and out of the resource node.

Equation (4) represents the generalized mass balance that is applicable to all the cumulative resources:

$$
\begin{aligned}
R_{r, t}=R_{r, t-l}+\sum_{k \in K^{C} \cup K^{B}} O_{r, k, t-d d_{r, k}}-\sum_{k \in K^{C} \cup K^{B}} I_{r, k}+\sum_{k \in K^{C} \cup K^{B}} U O_{r, k, t-d d_{r, k}}-\sum_{k \in K^{C} \cup K^{B}} U I_{r, k, t}+I n_{r, t}-O u t_{r, t} \\
\forall r \in R^{C}, \forall t \in 1, . ., T
\end{aligned}
$$

The cumulative resource mass balances are completed by the following additional constraints. The initial amount $R O_{r}$ of resource $r$ is supposed to be known:

$$
R_{r, 0}=R O_{r} \quad \forall r \in R^{C} \cup R^{S}
$$

Minimum and maximum bounds on the imports (parameters $I n_{r}^{\min }$ and $I n_{r}^{\max }$ ) and exports (parameters $O u t_{r}^{\min }$ and $O u t_{r}^{\max }$ ) of resource $r$ in period $t$ are given by equations (6) and (7): 


$$
\begin{aligned}
& \text { Out }_{r, t}^{\min } \leq \text { Out }_{r, t} \leq \text { Out }_{r, t}^{\max } \quad \forall r \in R^{C} \\
& I n_{r, t}^{\min } \leq I n_{r, t} \leq \operatorname{In}_{r, t}^{\max } \quad \forall r \in R^{C}
\end{aligned}
$$

The demands $D_{r, t}$ of cumulative resource $r$ (finished product) in period $t$ are supposed to be known (production planning). They are met by using equations (8).

$$
\text { Out }_{r, t}^{\min }=\text { Out }_{r, t}^{\max }=D_{r, t} \quad \forall r \in R^{C}
$$

\subsection{Processing of cumulative resources}

Tasks can transform cumulative resources in known or unknown proportions of batch size. In this last case, the proportions are calculated through the resolution of the optimization problem and need to be constrained by means of individual mass balance equations written for each task node. The mass balance around the task node is displayed in the graphical representation by using the fixed and free flow arcs entering and leaving the task node (figure 11).

Equations (9) and ( 0) simply indicate that the batch size $B_{k}$, of a task $k$ at time interval $t$ is equal to he sum of the amount $I_{r, k, t}$ of resource $r$ ent ing in task $k$ as well as the amount $O_{, r, k, t}$, resource $r$ leaving the task $k$.

$$
\begin{aligned}
& B_{k, t}=\sum_{r \in R_{k}^{\text {cons }}} I_{r, k, t} \quad, \in K, \forall t \in 1, \ldots, T \\
& B_{k, t}=\sum_{r \in R_{k}^{\text {Prod }}} O_{r, k, t} \quad \in K, \forall t \in 1, \ldots, T
\end{aligned}
$$

Furthermore, the amuunt of input and output flows into and out oi a task $k$ needs to be constrained. Starting with the outputs from the task, they are constrained by equations (12) and (13).

$$
\begin{array}{ll}
O_{r, k, t} \leq\left(\rho_{k, r}^{\text {prod }}+\mu_{k, r}^{\text {prod }}\right) . B_{k, t} & k \in K, \forall r \in R_{k}^{\text {prod }}, \forall t \in 1, \ldots, T \\
O_{r, k, t} \geq \rho_{k, r}^{\text {prod }} B_{k, t} & k \in K, \forall r \in R_{k}^{\text {prod }}, \forall t \in 1, . ., T
\end{array}
$$

If a fixed flow arc exists between resource $r$ and task $k\left(0 \leq \rho_{k, r}^{\text {prod }} \leq 1\right.$ and $\left.\mu_{k, s}^{\text {prod }}=0\right)$, then equations (12) and (13) become $O_{r, k, t}=\rho_{k, r}^{\text {prod }} B_{k, t}$. However, if a free flow arc exists between resource $r$ and task $k\left(\rho_{k, r}^{\text {prod }}=0\right.$ and $\left.\mu_{k, s}^{\text {prod }}=1\right)$, then equations (12) and (13) become $0 \leq O_{r, k, t} \leq B_{k, t}$. In the same vein, the following equations take into account the resource $r$ entering the task $k$ :

$$
\begin{aligned}
& I_{r, k, t} \leq\left(\rho_{k, r}^{\text {cons }}+\mu_{k, r}^{\text {cons }}\right) B_{k, t} \quad \forall k \in K, \forall r \in R_{k}^{\text {cons }}, \forall t \in 1, \ldots, T \\
& I_{r, k, t} \geq \rho_{k, r}^{\text {cons }} B_{k, t} \quad \forall k \in K, \forall r \in R_{k}^{\text {cons }}, \forall t \in 1, \ldots, T
\end{aligned}
$$

\subsection{Production/consumption of cumulative resources}

- Consumption of a cumulative resource 
The consumption of a cumulative resource is displayed in the graphical representation by a consumption arc (figure 7.a). The amount of cumulative resource consumed by different processing tasks is quantified by equation (16). The amount $U I_{r, k, t}$ of cumulative resource $r$ consumed by a task $k$ comprises a constant term $u f_{k, r}^{c o n s}$ and a variable term dependent on the batch size defined by the parameter $u v_{k, r}^{\text {cons }}$.

$$
U I_{r, k, t}=u f_{k, r}^{c o n s} W_{k, t}+u v_{k, r}^{c o n s} \sum_{t^{\prime}=t-p_{k}+l}^{t} B_{k, t^{\prime}} \quad \forall r \in R^{C}, \forall k \in K, \forall t \in 1 . . T
$$

\section{- Production of cumulative resource}

The production of cumulative resource is displayed in the graphical representation by a production arc (figure 7.b) and arises from the execution of a processing task. The amount $U O_{s, k, t}$ of cumulative resource $r$ produced by a task $k$ comprises a constant term $u f_{k, r}^{\text {prod }}$ and a variable term dependent on the batch size defined by the parameter $u v_{k, r}^{p r o d}$.

$$
U O_{r, k, t}=u f_{k, r}^{p r o d} W_{k, t}+u v_{k, r}^{p r o d} \sum_{t^{\prime}=t-p_{k}+1}^{t} B_{k, t^{\prime}} \quad \forall r \in R^{C}, \forall k \in K, \forall t \in 1 . . T
$$

\subsection{State resources balance}

In conjunction with equations (2) and (5), equation (18) represents the transition between states of a resource. Parameters $\alpha_{k, r}^{\text {prod }}$ and $\alpha_{k, r}^{\text {cons }}$ are different from zero if an arc exists between the state resource $r$ and the task $k$.

$$
R_{r, t}=R_{r, t-1}+\sum_{k \in K^{C} \cup K^{B}} \alpha_{k, r}^{\text {prod }} W_{k, t-d d_{r, k}}-\sum_{k \in K^{C} \cup K^{B}} \alpha_{k, r}^{c o n s} W_{k, t} \quad \forall r \in R^{S}, \forall t \in 1, \ldots, T
$$

\section{Application}

In order to illustrate the use of ERTN formalism, this section focuses on the modeling of a complete production site (production unit and $C H P$ plant).

\subsection{General description of the industrial site}

The production unit considered in this study converts three feeds (A, B and C) into four intermediate products (HotA, intBC, int $\mathrm{AB}$ and ImpurE) and two finished products (P1 and P2). Four pieces of process equipment (Preheater, Reactor 1, Reactor 2 and Separator) are used which consume electricity and steam at high pressure (XP), medium pressure (MP) and low pressure (LP). Three reactions $(R 1, R 2$ and $R 3$ ) can take place either in Reactor 1 or in Reactor 2 . The procedure associated with the generic recipe of the product is shown in figure 12. 
The production plant in this case study is a flow shop including three different production lines. The plant topology in the figure 13 shows that the production plan uses only 5 processing pieces of equipment to perform the 9 process operations (reactions $R l-R 9$ ).

For this reason, a resource allocation matrix (table 2) indicates which equipment could be used to perform the processing operations (reaction $R I-R 9$ ) and the corresponding duration. Since each reactor may be the site of several reactions, a total of 15 tasks can be performed in this unit.

To complete the information about the batch production plant, a utility consumption matrix (table 3 ) provides the details about the subset of utility consumed during the execution of each processing task.

The parameters associated with the batch task and cumulative resources are summarized in table 4.

The utility system considered for this study is inspired by the $C H P$ plant proposed by Soylu et al. (2006). Its topology is presented in figure 14.

This utility system includes two boilers for generating $H P$ steam, two multi-stage steam turbines for generating electricity, one $H P R V$ for converting $H P$ steam into $M P$ steam and one $M P R V$ to convert $M P$ steam into $L P$ steam. Alternatively, the $M P$ and $L P$ steam requirements of the production plant can be fulfilled by using steam extraction from multi-stage turbines. The advantage of using a turbine is that it not only reduces pressure but also simultaneously generates electricity. The parameters of the site recipe of this $C H P$ system are given in table 5 .

Finally, the decision system had to adhere to a schedule to meet the production demands (delivered at the end of the planning horizon comprising $T$ periods) and in the meantime, keep operational costs as low as possible.

\subsection{ERTN modelling of the industrial site}

For the sake of clarity, the ERTN graphical representation is divided into two charts and the parameters of tasks and resource nodes are not indicated (given by the previous tables). Moreover, the link between the two units is provided by the flow of utilities and indicated with labels: LP (label 1), MP (label 2), HP (label 3) and ELEC 
(label 4). The ERTN graphical representation of the batch production unit is shown in figure 15 while the ERTN representation of the CHP unit is given in figure 16 .

Information highlighted in Table 2 and Table 3 is summarized in the graphical representation. The task nodes, the cumulative resource node and the fixed flow arcs define the product recipe. The disjunctive resource nodes and "use" arcs, in conjunction with task nodes, express the plant topology. The utility consumption matrix is conveyed by the cumulative resources and production/consumption flow arcs. Since the utility consumptions are only dependent on the batch-size, the fixed coefficient on utility consumption arcs is always 0 . The nuance between flow arcs and production/consumption arcs is illustrated on several cumulative resource nodes. For example, the HP steam resource acts as a produced material resource for the boiler and as a consumed utility resource for Reactor 1 and Reactor 2. For this reason, the $H P_{\text {steam }}$ node is connected to the boiling task by using a fixed flow arc and to the reaction tasks using a consumption arc.

This example illustrates the heterogeneity of the production mode where the production plant is composed of discontinuous unit operations and the site utility system is a continuous process with frequent changes in operating conditions. Consider the ERTN of figure 17 which is a part of the ERTN presented in figure 15 and figure 16.

The duration of Reaction 1 is 2 hours and it can take place either in Reactor 1 (batch task $\mathrm{T}_{1}$ ) or Reactor 2 (batch task $\mathrm{T}_{2}$ ). To perform these tasks, a continuous feed of $H P$ steam is required ( $0.1 \mathrm{tons} / \mathrm{hr} / \mathrm{kmol}$ of material being processed) and is fulfilled by the Boiler (continuous task $\mathrm{T}_{16}$ ). This utility demand is satisfied by continuous tasks in the utility system that instantaneously transforms (i.e. without any time delay) water into HP steam. This example illustrates the notion of delivery time introduced in section 3.1. In this case, the processing and delivery times of the reactor are equal to 2 periods. In contrast, the processing time is equal to 1 while the delivery time is equal to 0 because the conversion is presumed "instantaneous" (figure 18).

An example of a Gantt chart and characteristic profiles of the production plant and site utility system are represented in figure 18 . Two batches of $10 \mathrm{~kg}$ and one batch of $30 \mathrm{~kg}$ of material B are produced respectively in Reactor 2 (task $\mathrm{T}_{2}$ ) and Reactor 1 (task $\mathrm{T}_{1}$ ). To meet the HP steam demand of Reactor $1(3 \mathrm{t} / \mathrm{h})$ and Reactor $2(1 \mathrm{t} / \mathrm{h})$ during the time period 3 , the boiler (task $\mathrm{T}_{16}$ ) supplies $4 \mathrm{t} / \mathrm{h}$ of HP steam throughout this time 
period 3. Hence, the operations of the site utility system are continuous but with multiple operating points.

Unlike their production unit counterparts, some tasks in site utility systems do not produce material resources in fixed proportions. Here, steam extraction from a multistage turbine depends on the $M P$ and $L P$ steam demand of the production unit. The amount of steam extraction at each turbine stage is variable and can take any value between zero and an upper bound (figure 16).

\subsection{Refinement of the modelling}

Additional elements could be introduced to the ERTN shown in figure 15 and figure 16 to refine the process modeling.

\subsubsection{Case of non-linear functions}

Previously, it was assumed that all parameters are defined as linear functions. When non-linear functions must be taken into account, they are first transformed into piecewise continuous functions. The corresponding task is then duplicated for each resulting interval. Figure 19 illustrates this point with the modeling of the boiler. The fuel consumption in a boiler is given by the equation (19):

$$
I=\frac{\Delta h_{\text {diff }} \cdot X H P}{c c \cdot \eta}
$$

Where XHP is the amount of high pressure $(H P)$ steam produced, $c c$ refers to the calorific value of fuel, $\eta$ is the boiler efficiency and $\Delta h_{\text {diff }}$ is the difference in enthalpy between superheated steam and feed-water. It is assumed that steam pressures and temperatures are fixed at the boiler inlet and outlet, thus turning the difference in enthalpy into a parameter. However, there are still two variables in the equation boiler: efficiency $\eta$ and fuel consumption $I$. In order to include the effect of efficiency variation with varying load factor, the corresponding non linear function is divided into three linear pieces. $X H P_{\max }$ is the maximum capacity of the boiler and $X H P_{\min }$ is the minimum amount of steam that can be produced (below this steam level, it is not economically viable to operate the boiler and it is shut down). As a consequence, boiler task is modeled by three different tasks. The $V_{k}^{\min }$ and $V_{k}^{\max }$ of each task node are defined by the end points on the piecewise linear curve.

\subsubsection{Case of multi-modal devices}

Some complex devices can pass through different operating modes over time. Concerning the CHP plant, the boiler is an example of this feature (figure 20). The 
boiling operation is presumed continuous as long as the boiler is in an active state. Moreover, it is assumed that switching from the idle to active state is instantaneous. However, once shut down (idle state), the boiler needs to go through a set-up phase. During this phase, the boiler consumes fuel but does not produce HP steam of required quality. To model this feature, state resource nodes are introduced in order to manage the legal sequences of switching between these different states.

Another example, showing the use of state resource nodes, concerns a distillation column. This device must first start-up before reaching a steady state. So, a state resource is added in the time between these two tasks. Shut-down phase is managed in the same way. A zero-wait policy is associated with these two state resource nodes since these three tasks must be consecutive (figure 21).

State resource nodes can also help to manage sequence dependent cleaning operations or frequency dependent cleaning operations. In the first case (figure 22.a), if a task Reaction 1 is followed by a task Reaction 2 for example, the node Sr2 requires that a cleaning task NEP $1 \rightarrow 2$ have been inserted. In the second case (figure 22.b), the node $\mathrm{Sr} 1$ binds to perform a cleaning task NEP in order to reset the counter to 6 and thus, allows the successive execution of five Reaction tasks.

\subsection{Results}

While Agha et al. (2010 have already demonstrated the benefits of integrated management compared to a master/slave approach, only a single scheduling example is presented in this paper. The above mentioned example was formulated and resolved using software XPRESS-MP release 2008A. The objective function is a cost criterion including the fuel cost and emissions costs. The problem was solved on an Intel(R) Core(TM) 2 Duo CPU @ $2.00 \mathrm{GHz}$ and $1.00 \mathrm{~GB}$ of RAM. A 24-hour planning horizon is considered with the time intervals divided into 24 one-hour periods. The demands are such that the batch plant is presumed to be working at $90 \%$ of maximum capacity. Figure 23 presents the Gantt chart resulting from the combined scheduling of the whole plant. It can be observed that the tasks in the production plant are arranged in such a manner that maximizes the potential of the CHP plant. Indeed, the location of the production tasks is calculated in order to have as many utility cascades (requirement of at least two different utilities at the same time and duration) as possible. Compared to a "master/slave" approach, Agha et al. (2010) have shown that this model leads to a reduction of cost of between 15 and $30 \%$ (depending on the load ratio). 
Finally, figure 24 presents the steam curves resulting from the two approaches. They show the variation of steam at different pressure levels in the utility system with respect to time. In the master/slave approach, haphazard and quick variations in the steam curves are observed, knowing that some peaks of consumption may not be satisfied. In contrast, in the case of the integrated approach, the consideration of the utility system capacity and operation results in a smoothing of the steam curves. This is an interesting point because this leads to a more controllable CHP process and would also enable a $C H P$ plant of reduced capacity to be designed.

\section{Tools developed}

As mentioned previously, any semantic element of ERTN formalism has a direct translation to sets of constraints of the mathematical model. This presents the generic nature of this model since each instance of a problem is simply defined through a data file. Figure 25 summarizes the main steps of this procedure.

In order to facilitate the entry of parameters, a "drag and drop tool" has been developed. The user can create its ERTN graphically and define all the parameters (units, tasks, durations, sequences ...) of its model. A major interest of this modelling software attached to the ERTN graphical formalism is that the rules of construction are required to be satisfied in order to obtain a consistent model due to an automatic and formal checking procedure. After verification of the validity of the ERTN model, the program generates the initialization file that is compatible with the optimization model implemented in Xpress MP. After the scheduling phase, the user can proceed directly to a first analysis based on the Gantt diagram. For this, a second tool directly interprets the data provided by the optimizer and displays it as a Gantt chart with the evolution of the amount of states and batches on the time horizon (see Figure 26).

\section{Conclusion}

This paper has presented part of the results from the project GIMEP obtained in the framework of the "Programme Interdiciplinaire Energie" of CNRS. The general objective of this research is the development of solutions fo rational and efficient energy management in mono and multi-site process systems. In order to study various management strategies, the development of tools to uniformly model all considered production systems (production unit and site utility systems) in a systematic and unambiguous manner became necessary. To meet this goal, the ERTN graphical formalism has been proposed. Based on previous well-known graphical representation, the ERTN is then designed for the modeling of industrial units composed of disjunctive but also cumulative resources such as utilities. The main 
extensions of ERTN formalism lie in a clear identification of batch and continuous tasks (through the distinction between processing time and delivery time parameters), the introduction of free flow arcs (allowing the inlets and outlets of the task to be in variable proportions of batch-size), the introduction of production/consumption arcs (flow not governed by a conservative mass balance) and the definition of state resource nodes and transition arcs to model the states of multi-modal devices.

Another strength point of the ERTN formalism is the direct relationship that it creates between the graphical representation and the mathematical formulation based on the MILP tool. Each set of semantic elements (combination of nodes and arcs) corresponds to a structured set of mathematical constraints dependent only on parameters. The interesting factor of this generic aspect is the ability to model a wide range of systems while ignoring the mathematical model used to solve the problem. Moreover, this paves the way for the development of a software package providing a friendly $G U I$ to end-users who are not experts in optimization.

In this paper, the use of the ERTN graphical formalism has been applied to the combined scheduling of a batch unit and a site $C H P$ system producing an electricity and water derivative utility. Obviously, this framework could be used to deal with other utilities such as cooling fluid or compressed air for example.

On this basis, several lines of research are currently under development. First, it seems important to consider the concept of energy integration in our models. Indeed, being a potential source of improvement in energy efficiency, this concept is well defined for continuous processes. However, as yet, batch processes remain to be studied in the same way. Secondly, the discrete time model presented in this paper could be replaced by a continuous time formulation. The objective is to obtain a finer temporal location of utility production and consumption while avoiding the combinatorial explosion of the mathematical model. In this context, the development of a hybrid optimization method, combining the MILP model with dynamic simulation and/or constraint programming, is also planned. Finally, the generalization of the approach to "eco-industrial parks" is also projected.

\section{Nomenclature}

\begin{tabular}{|ll|}
\hline Sets & \\
$K$ & Set of tasks $k$ where a task $k=$ (Operation, Device) and $K=K^{B} \cup K^{C}$ \\
$K^{B}$ & Set of batch tasks \\
$K^{C}$ & Set of continuous tasks \\
$K_{r}$ & Set of tasks $k(k \in K)$ that can be performed by the disjunctive resource \\
& $r\left(r \in R^{D}\right)$ \\
$R$ & Set of resource $r$ with $R=R^{C} \cup R^{D} \cup R^{S}$ \\
$R^{C}$ & Set of cumulative resource $r$ \\
$R^{D}$ & Set of disjunctive resource $r$ \\
\hline
\end{tabular}




\begin{tabular}{|c|c|c|}
\hline$R^{S}$ & Set of state resource $r$ & \\
\hline$R_{k}^{\text {cons }}$ & Set of cumulative resource $r\left(r \in R^{C}\right)$ consumed by task $k(k \in K)$ & \\
\hline$R_{k}^{\text {prod }}$ & Set of cumulative resource $r\left(r \in R^{C}\right)$ produced by task $k(k \in K)$ & \\
\hline \multicolumn{3}{|c|}{ Variables } \\
\hline$W_{k, t}$ & $\begin{array}{l}\text { Allocation variable. } W_{k, t}=1 \text { if task } k \text { is launched at start of period } t \text {, } \\
W_{k, t}=0 \text { otherwise. }\end{array}$ & \\
\hline$B_{k, t}$ & Batch size (resp. flow rate) of the task $k, k \in K^{B}\left(\right.$ resp. $\left.k \in K^{C}\right)$ in period $t$ & $\mathrm{~kg}(\operatorname{ton} / \mathrm{h})$ \\
\hline$I_{r, k, t}$ & $\begin{array}{l}\text { Quantity (resp. flow) of cumulative resource } r\left(r \in R^{C}\right) \text { entering in task } \\
k, k \in K^{B}\left(\text { resp. } k \in K^{C}\right) \text { in period } t \text { and governed by a mass balance }\end{array}$ & $\mathrm{kg}(\operatorname{ton} / \mathrm{h})$ \\
\hline$O_{r, k, t}$ & $\begin{array}{l}\text { Quantity (resp. flow) of cumulative resource } r\left(r \in R^{C}\right) \text { leaving task } k \text {, } \\
k \in K^{B}\left(\text { resp. } k \in K^{C}\right) \text { in period } t \text { and governed by a mass balance }\end{array}$ & $\mathrm{kg}(\operatorname{ton} / \mathrm{h})$ \\
\hline$S_{r, t}$ & Amount of resource $r, r \in R^{C} \cup R^{S}$ available at start of period $t$ & $\mathrm{~kg}$ \\
\hline$U I_{r, k, t}$ & $\begin{array}{l}\text { Amount (resp. flow) of cumulative resource } r, r \in R^{C} \text { consumed by task } \\
\left.k, k \in K^{B} \text { (resp. } k \in K^{C}\right) \text { in period } t \text { and not governed by a mass balance }\end{array}$ & $\mathrm{kg}(\operatorname{ton} / \mathrm{h})$ \\
\hline$U O_{r, k, t}$ & $\begin{array}{l}\text { Amount (resp. flow) of cumulative resource } r, r \in R^{C} \text { produced by task } \\
k, k \in K^{B}\left(\text { resp. } k \in K^{C}\right) \text { in period } t \text { and not governed by a mass balance }\end{array}$ & $\mathrm{kg}(\operatorname{ton} / \mathrm{h})$ \\
\hline$I n_{r, t}$ & $\begin{array}{l}\text { Amount of imported cumulative resource } r, r \in R^{C} \text { from an external } \\
\text { source in period } t\end{array}$ & $\mathrm{~kg}(\operatorname{ton} / \mathrm{h})$ \\
\hline Out $_{r, t}$ & $\begin{array}{l}\text { Amount of exported cumulative resource } r, r \in R^{C} \text { toward an external } \\
\text { consumer in period } t\end{array}$ & $\mathrm{~kg}(\operatorname{ton} / \mathrm{h})$ \\
\hline \multicolumn{3}{|c|}{ Parameters } \\
\hline$C_{r}^{\max }$ & Maximum storage capacity of resource $r, r \in R^{C} \cup R^{S}$ & $\mathrm{~kg}$ \\
\hline$V_{k}^{\min }$ & Minimum batch size (resp. flow rate) of task $k, k \in K^{B}$ (resp. $k \in K^{C}$ ) & $\mathrm{kg}(\operatorname{ton} / \mathrm{h})$ \\
\hline$V_{k}^{\max }$ & Maximum batch size (resp. flow rate) of task $k, k \in K^{B}$ (resp. $\left.k \in K^{C}\right)$ & $\mathrm{kg}(\operatorname{ton} / \mathrm{h})$ \\
\hline $\operatorname{In}_{r, t}^{\min }$ & Minimum importation of resource $r, r \in R^{C}$ in period $t$ & $\mathrm{~kg}(\operatorname{ton} / \mathrm{h})$ \\
\hline$I n_{r, t}^{\max }$ & Maximum importation of resource $r, r \in R^{C}$ in period $t$ & $\mathrm{~kg}(\operatorname{ton} / \mathrm{h})$ \\
\hline$O u t_{r, t}^{\min }$ & Minimum exportation of resource $r, r \in R^{C}$ in period $t$ & $\mathrm{~kg}(\operatorname{ton} / \mathrm{h})$ \\
\hline Out $t_{r, t}^{\max }$ & Maximum exportation of resource $r, r \in R^{C}$ in period $t$ & $\mathrm{~kg}(\operatorname{ton} / \mathrm{h})$ \\
\hline $\mathrm{SO}_{\mathrm{r}}$ & Initial amount of resource $r, r \in R^{C} \cup R^{S}$ & $\mathrm{~kg}$ \\
\hline$D_{r, t}$ & Demand (production order) in resource $r, r \in R^{C}$ in period $t$ & $\mathrm{~kg}(\operatorname{ton} / \mathrm{h})$ \\
\hline$p_{k}$ & Duration of task $k, k \in K$ & $\mathrm{~h}$ \\
\hline$p f_{k}$ & Fixed part of the duration of task $k, k \in K$ & $\mathrm{~h}$ \\
\hline$p v_{k}$ & $\begin{array}{l}\text { Coefficient relative to the duration dependant of the batch size of task } k, \\
k \in K^{B}\end{array}$ & $\mathrm{k} / \mathrm{kg}$ \\
\hline$d d_{r, k}$ & Delivery time of resource $r, r \in R^{C} \cup R^{S}$ by task $k, k \in K$ & $\mathrm{~h}$ \\
\hline$\rho_{k, r}^{p r o d}$ & $\begin{array}{l}\text { Proportion of resource } r, r \in R^{C} \text { produced by task } k, k \in K \text {. } \\
\text { Comprise in } 0<\rho_{k, r}^{\text {prod }} \leq 1 \text { if a fixed flow arc exists between task } k \text { and } \\
\text { cumulative resource } r, 0 \text { otherwise }\end{array}$ & \\
\hline$\rho_{k, r}^{c o n s}$ & $\begin{array}{l}\text { Proportion of resource } r, r \in R^{C} \text { consumed by task } k, k \in K \text {. } \\
\text { Comprise in } 0<\rho_{k, r}^{\text {cons }} \leq 1 \text { if a fixed flow arc exists between cumulative } \\
\text { resource } r \text { and task } k, 0 \text { otherwise }\end{array}$ & \\
\hline$\mu_{k, r}^{\text {prod }}$ & $\begin{array}{l}\text { Equal to } 1 \text { if a free flow arc exists between task } k, k \in K \text { and cumulative } \\
\text { resource } r, r \in R^{C}, 0 \text { otherwise }\end{array}$ & \\
\hline$\mu_{k, r}^{\text {cons }}$ & $\begin{array}{l}\text { Equal to } 1 \text { if a free flow arc exists between cumulative resource } r, r \in \\
R^{C} \text { and task } k, k \in K, 0 \text { otherwise }\end{array}$ & \\
\hline
\end{tabular}




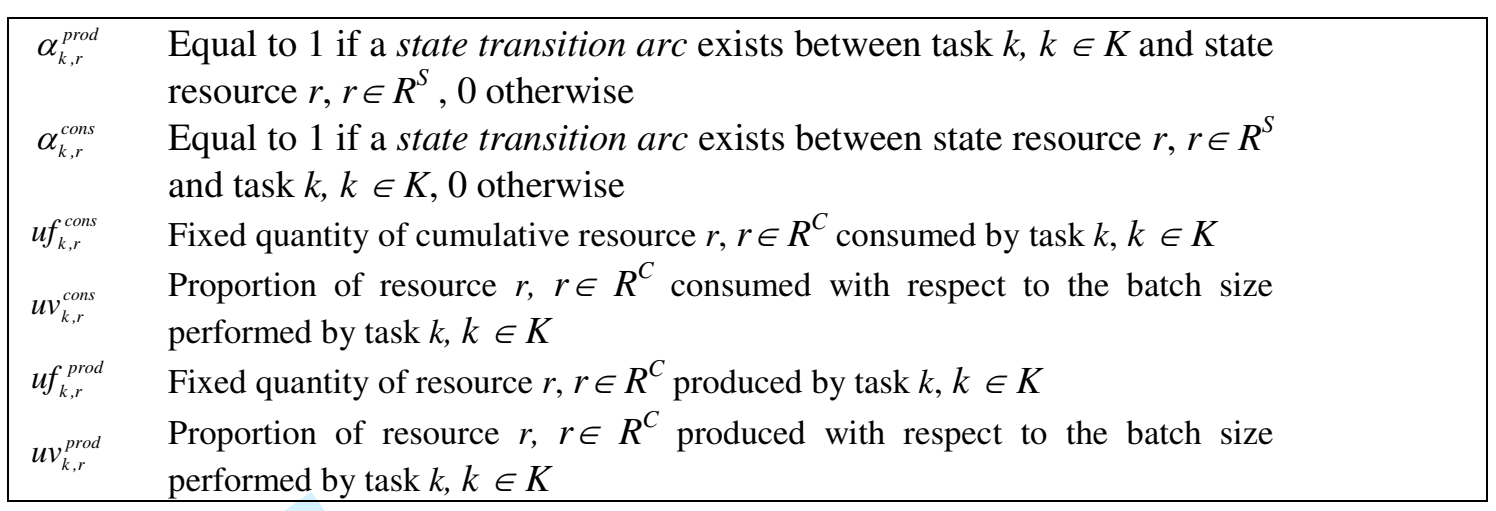

\section{References}

Agha M.H., 2009, Integrated Management of energy and production: scheduling of batch processes and CHP plants, PhD Thesis, INP Toulouse Agha M.H., Théry R., Hétreux G., Hait A., Le Lann J.M., 2009, Algorithm for integrated production and utility system scheduling of batch plants, Computer Aided Chemical Engineering, Vol.27, pp.1497-1502.

Agha M.H., Théry R., Hétreux G., Hait A., Le Lann J.M., 2010, Integrated production and utility system approach for optimizing industrial unit operation, 2010, Energy, Vol. 35, pp. 611-627.

Burkard R.E. et Hatzl J., 2005, Review, extensions and computational comparison of MILP formulations for scheduling of batch processes, Computers and Chemical Engineering, 29, 1752-1769

Behdani B., M.R. Pishvaie and D. Rashtchian, 2007, Optimal scheduling of mixed batch and continuous processes incorporating utility aspects, Chemical Engineering and Processing, 46(4), p. 271-281.

Grenelle de l'Environnement, 2009, Lutter contre les changements climatiques et maîtriser l'énergie, http://www.legrenelle-environnement.fr/spip.php?rubrique5

Floudas C.A. et Lin X., 2004, Continuous-time versus discrete-time approaches for scheduling of chemical processes: a review, Computers and Chemical Engineering, 28, 2109-2129

Hétreux G., Fabre F., Le Lann J.M., Zaraté P., Environnement de simulation dynamique hybride: application aux procédés discontinus, conférence MOSIM'10, Hammamet (Tunisie)

Kjaerheim G., 2005, Cleaner production and sustainability, Journal of Cleaner Production, 13(4), p. 329-339

Kallrath J., 2002, Planning and Scheduling in the process industry, OR Spectrum, 24, 219-250 
Kondili E., C.C. Pantelides and W.H. Sargent, 1988, A general algorithm for scheduling batch operations, $3^{\text {rd }}$ International Symposium Process Systems Engineering, Sydney, p. 62-75

Kuehr R., 2006, Towards a sustainable society: United Nations University's zero emissions approach, Journal of Cleaner Production, 15(13-14), p. 1198-1204

Méndez C.A., Cerdá J., Grossmann I.E., Harjunkoski I. et Fahl M., 2006, State-of-theart review of optimization methods for short-term scheduling of batch processes, Computers and Chemical Engineering, vol. 30, Issues 6-7, Pages 913-946

Pantelides C.C., 1994, Unified Framework For The Optimal Process Planning And Scheduling, CACHE Publications. Proceedings of the Second Conference on Foundations of Computer Aided Operations, p. 253-274.

Soylu A., C. Oruc, M. Turkay, K. Fujita and K. Asakura, 2006, Synergy Analysis of Collaborative Supply Chain Management in Energy Systems Using Multi-period MILP, European Journal of Operation Research, Vol. 174 (1), pp. 387-403.

Zhang, B.J. and B. Hua, 2005, Effective MILP model for oil refinery-wide production planning and better energy utilization, Journal of Cleaner Production, 15, p. 439-448. 


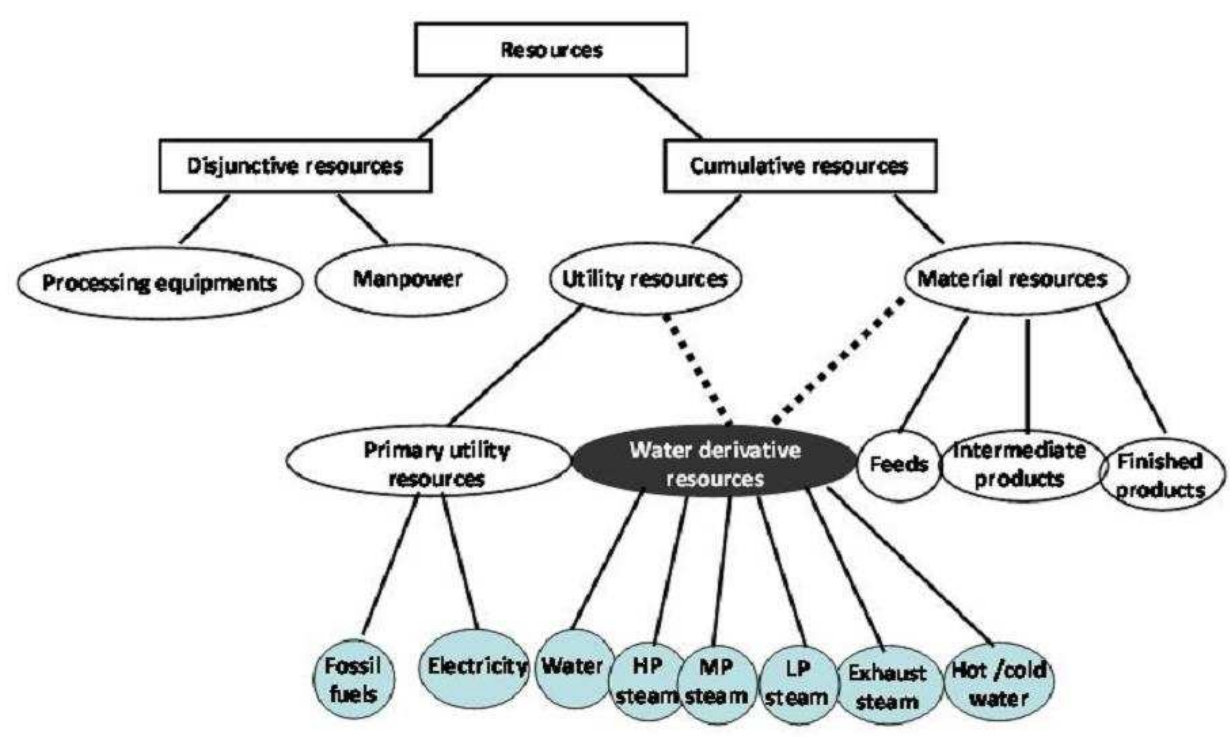

Duality of cumulative resources: case of water derivative resources $254 \times 190 \mathrm{~mm}(96 \times 96 \mathrm{DPI})$ 


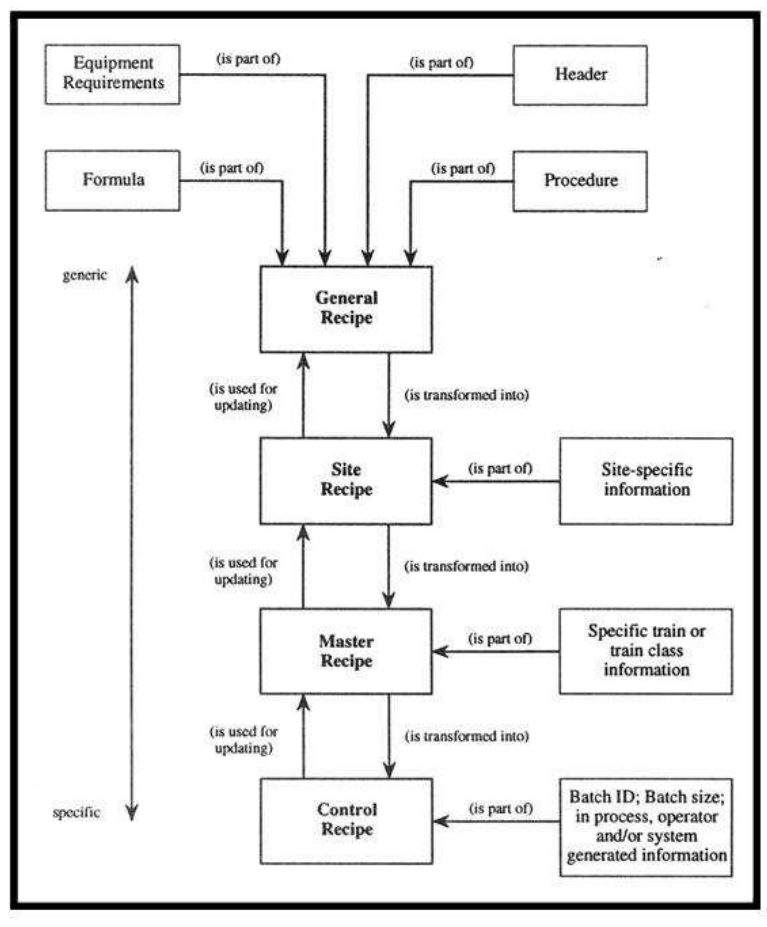

hierarchical model of the recipe $254 \times 190 \mathrm{~mm}(96 \times 96 \mathrm{DPI})$ 
batch (left) and continuous (right) task node $254 \times 190 \mathrm{~mm}(96 \times 96 \mathrm{DPI})$ 


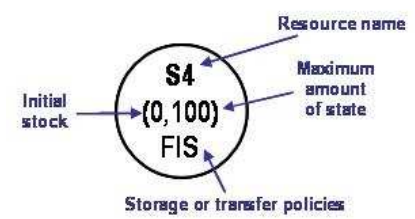

(a) - cumulative ressource node

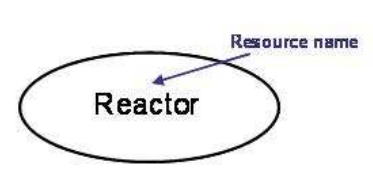

(b) - disjunctive ressource node

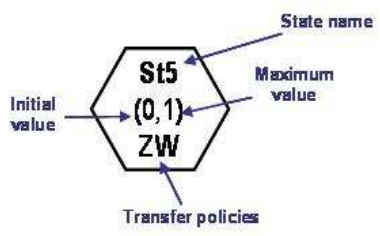

(c) - state ressource node

resource nodes of the ERTN formalism $254 \times 190 \mathrm{~mm}(96 \times 96 \mathrm{DPI})$ 


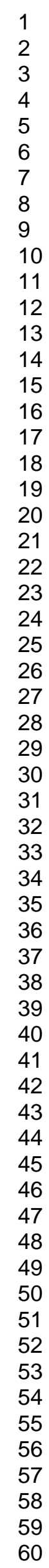
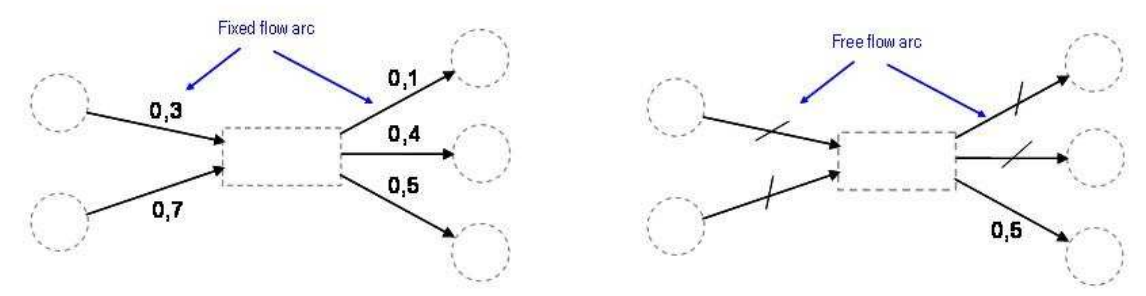

fixed and free flow arcs $254 \times 190 \mathrm{~mm}(96 \times 96$ DPI $)$ 


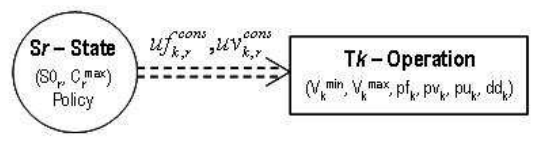

(a) Consumption of resource $r$ by task $k$

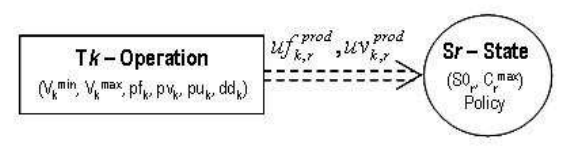

(b) Production of resource $r$ by task $k$

Consumption and Production flow arcs $254 \times 190 \mathrm{~mm}$ (96 x 96 DPI) 

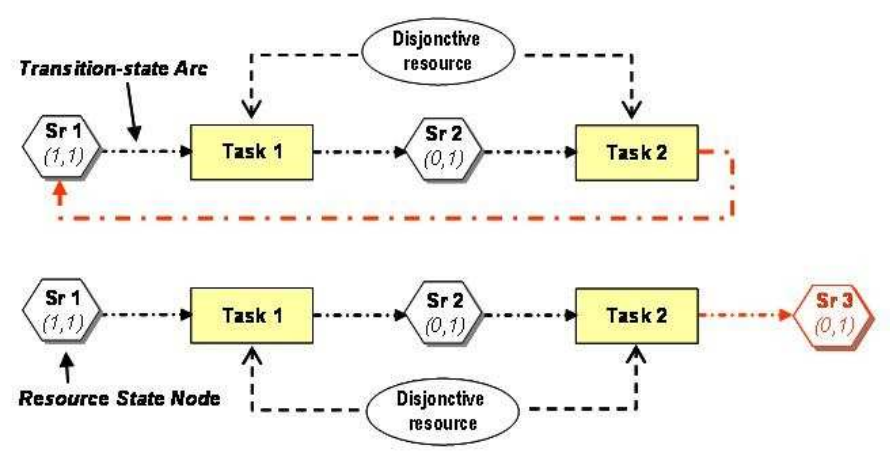

sequences of state resource nodes $254 \times 190 \mathrm{~mm}$ (96 x 96 DPI) (a) Cyclic sequence of state

(b) single sequence of state 
discrete time formulation of the scheduling problem $254 \times 190 \mathrm{~mm}(96 \times 96$ DPI) 


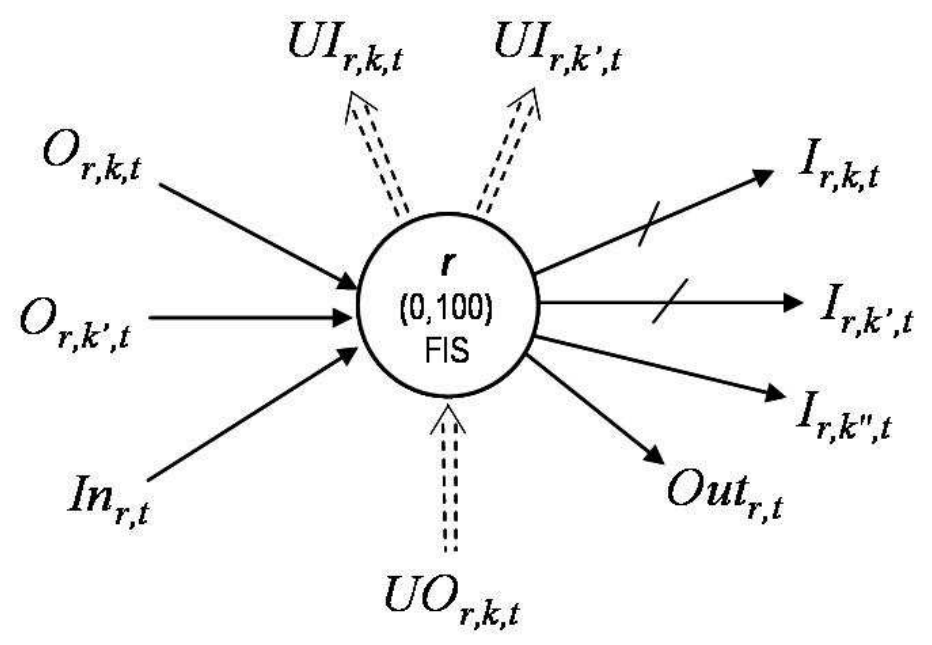

$$
\begin{aligned}
& \text { mass balance of a cumulative resource node } \\
& \text { 254x190mm (96 x 96 DPI) }
\end{aligned}
$$


task mass balances $254 \times 190 \mathrm{~mm}(96 \times 96 \mathrm{DPI})$ 

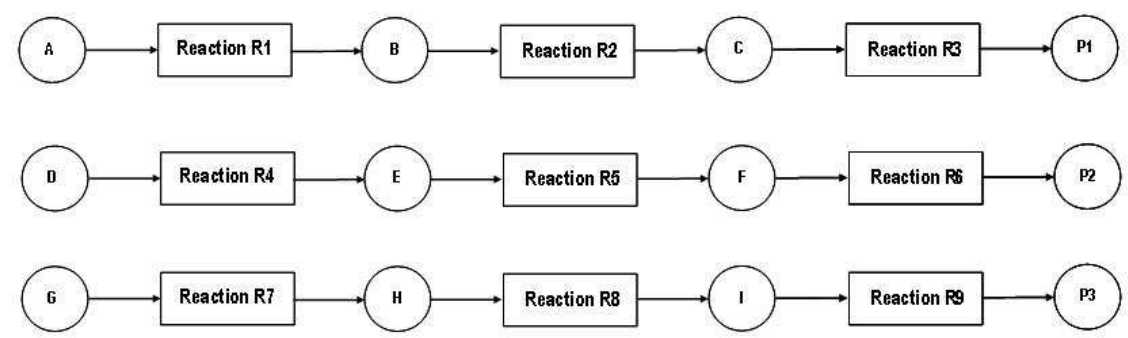

generic recipe of products $\mathrm{P} 1, \mathrm{P} 2$ and $\mathrm{P} 3$ $254 \times 190 \mathrm{~mm}(96 \times 96 \mathrm{DPI})$ 


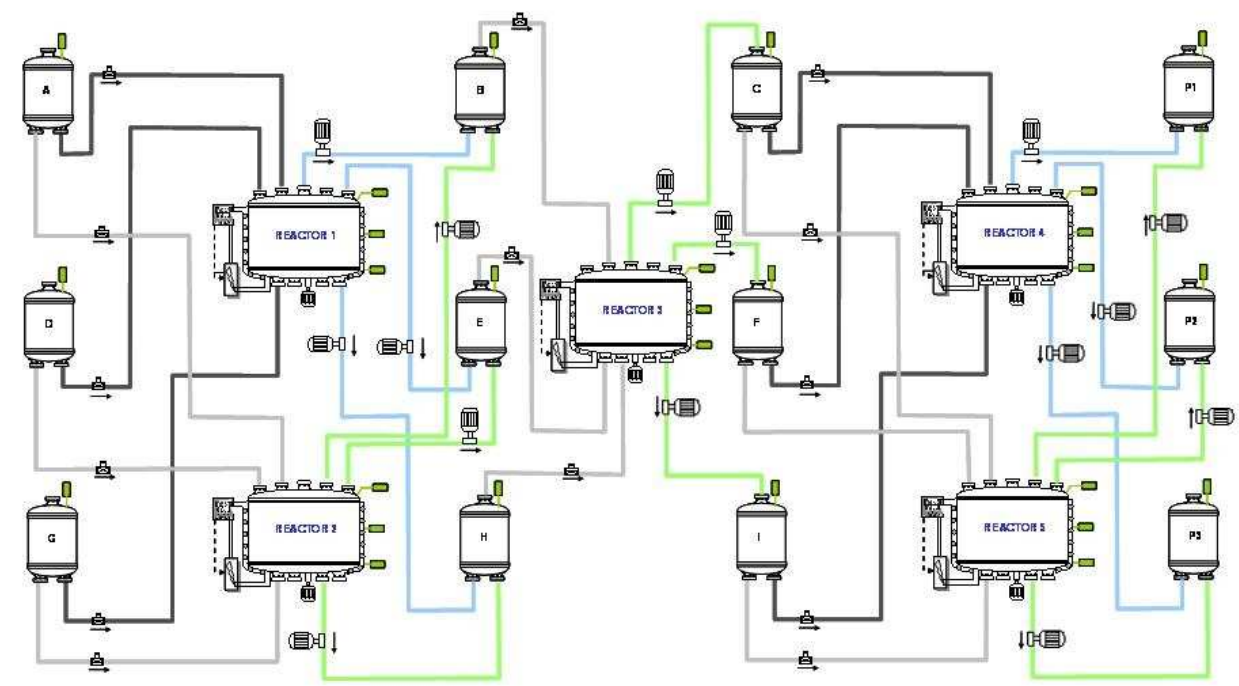

topology of the production unit $254 \times 190 \mathrm{~mm}$ ( $96 \times 96 \mathrm{DPI})$ 


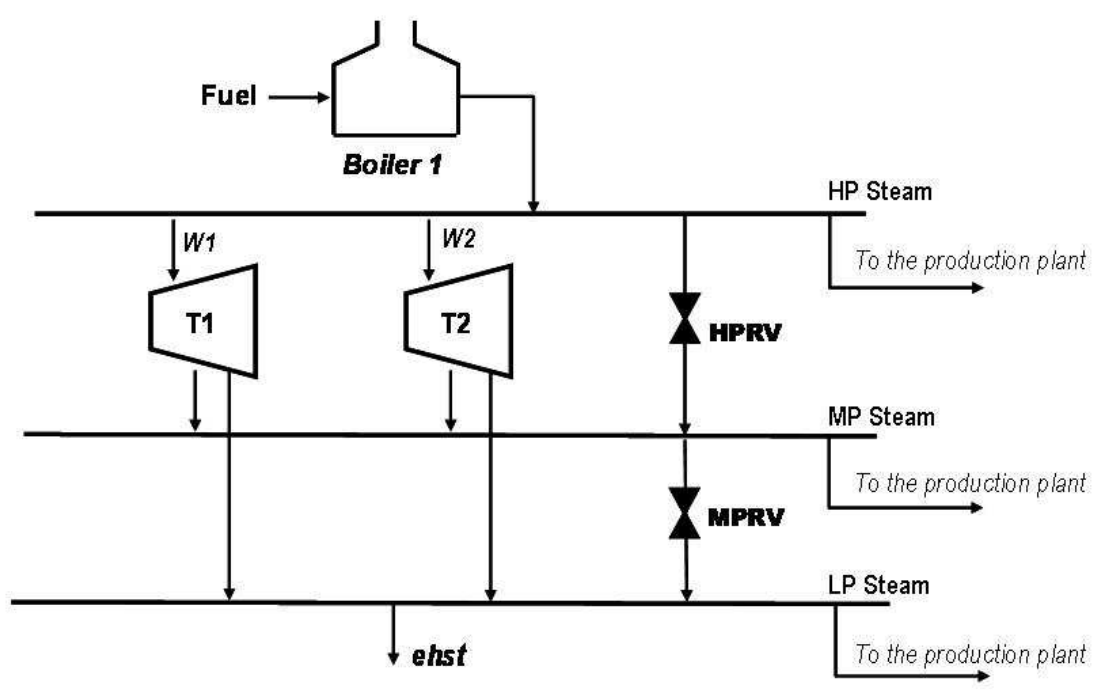

topology of the CHP plant $254 \times 190 \mathrm{~mm}(96 \times 96 \mathrm{DPI})$ 
ERTN modeling of the site recipe of the batch production unit $254 \times 190 \mathrm{~mm}(96 \times 96$ DPI) 


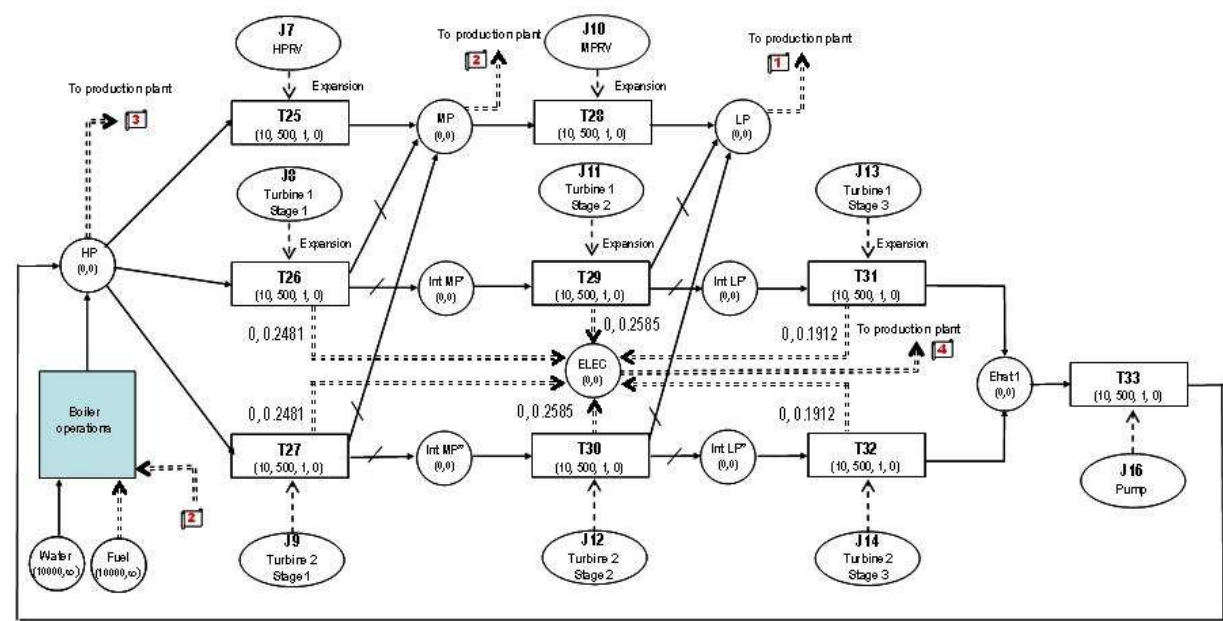

ERTN representation of the site recipe of the CHP plant $254 \times 190 \mathrm{~mm}(96 \times 96 \mathrm{DPI})$ 
Part of the ERTN of figure 15 and figure 16 $254 \times 190 \mathrm{~mm}(96 \times 96 \mathrm{DPI})$ 

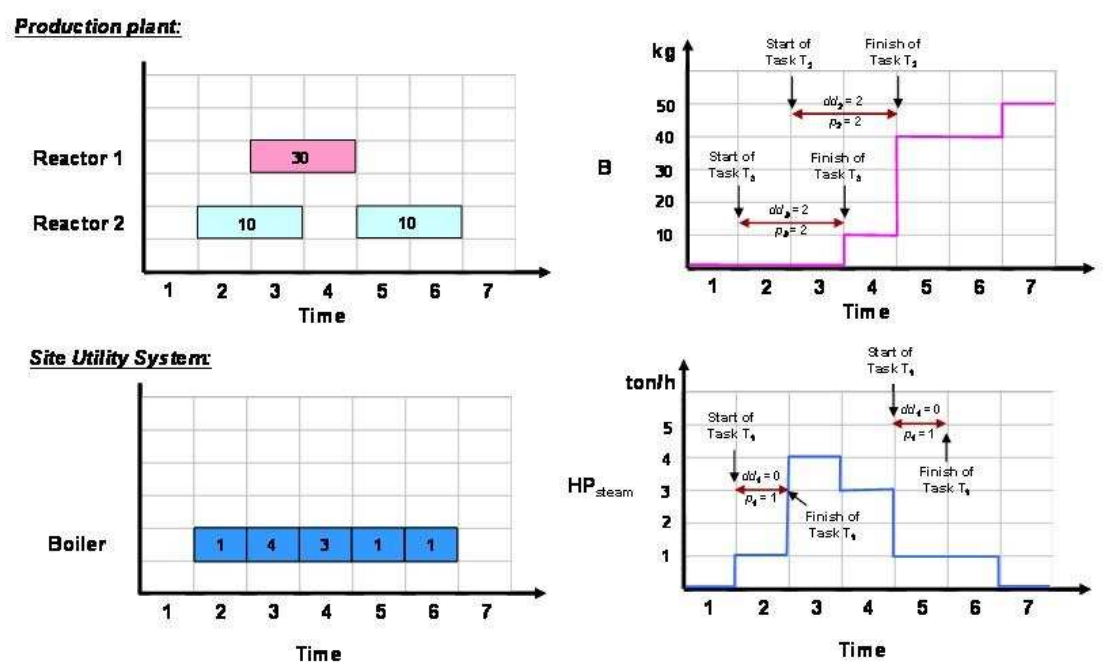

notion of delivery time in ERTN framework $254 \times 190 \mathrm{~mm}$ (96 x 96 DPI)

\footnotetext{
http://mc.manuscriptcentral.com/tprs Email: ijpr@lboro.ac.uk
} 

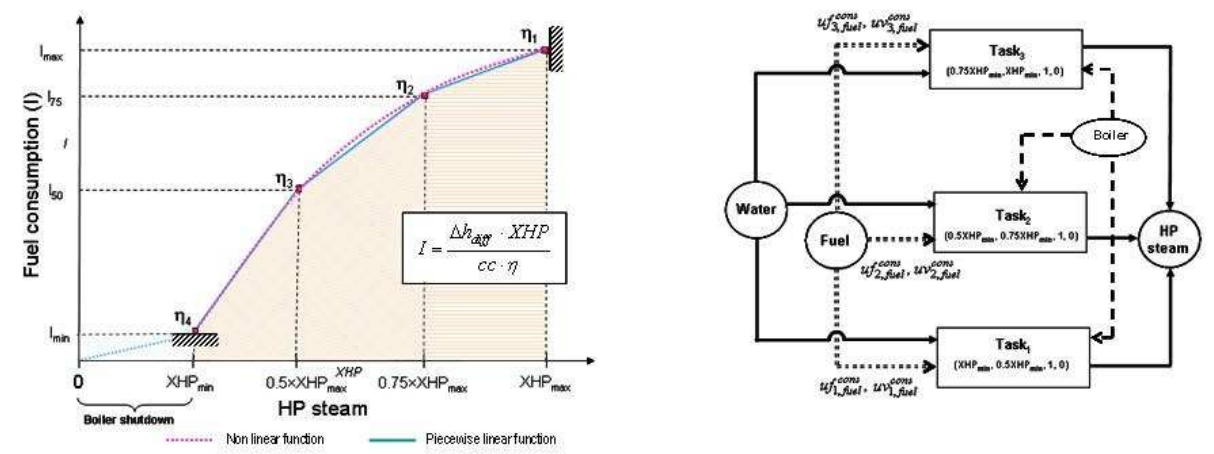

Non-linear function - application to the boiling efficiency $254 \times 190 \mathrm{~mm}(96 \times 96 \mathrm{DPI})$ 


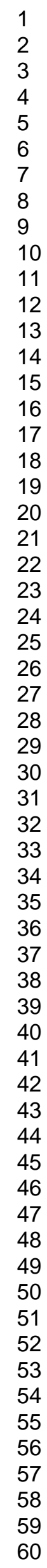

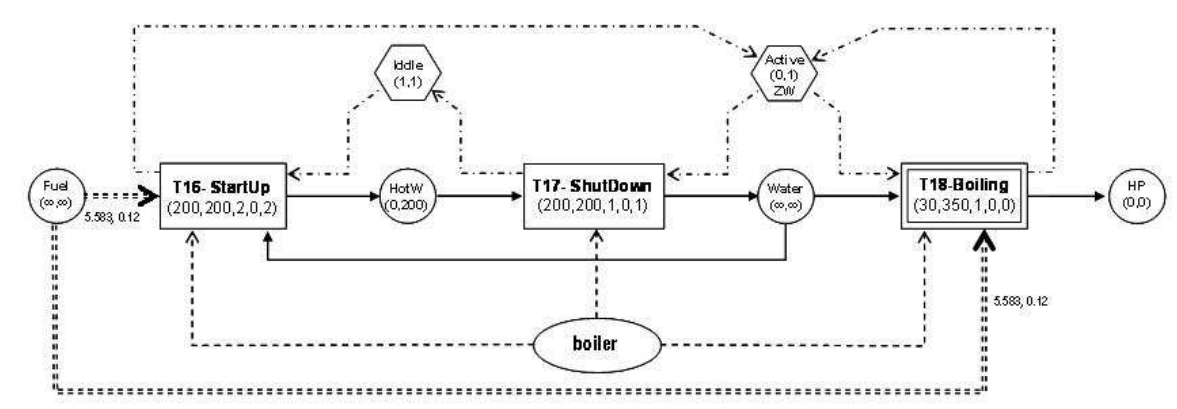

states of the boiler $254 \times 190 \mathrm{~mm}(96 \times 96$ DPI $)$

http://mc.manuscriptcentral.com/tprs Email: ijpr@lboro.ac.uk 

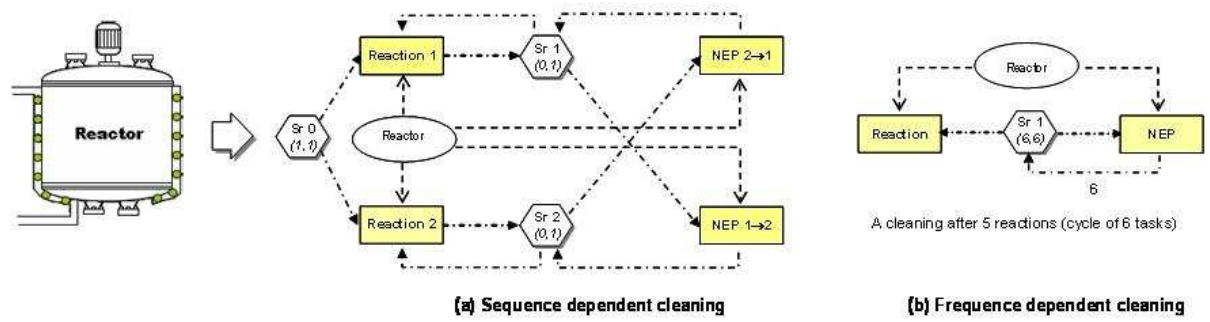

A cleaning after 5 reacions (cycle of 6 tasks)

(b) Frequence dependent cleaning

management of cleaning operations $254 \times 190 \mathrm{~mm}(96 \times 96 \mathrm{DPI})$ 
Scheduling of the production unit $254 \times 190 \mathrm{~mm}$ (96 x 96 DPI) 


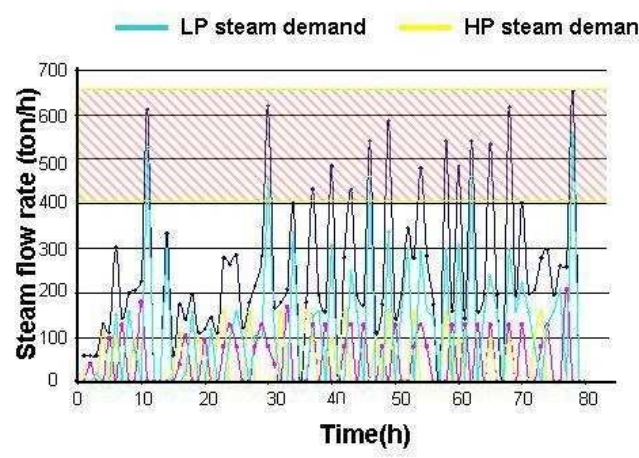

Master Slave Approach

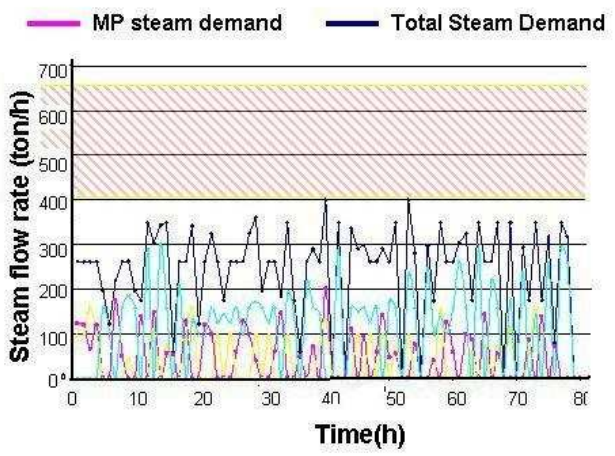

Master Slave Approach

Steam Curves

$254 \times 190 \mathrm{~mm}(96 \times 96$ DPI $)$ 


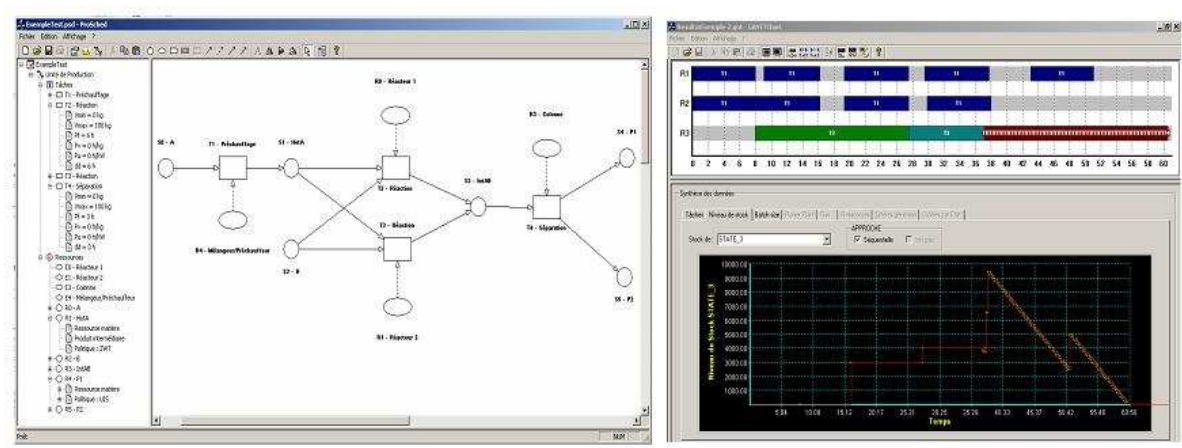

ProSched Generator and Gantt Chart Manager

$254 \times 190 \mathrm{~mm}(96 \times 96$ DPI $)$ 


\begin{tabular}{|c|c|c|}
\hline NOM & SYMBOLE & REPRESENTS \\
\hline $\begin{array}{l}\text { Batoh task } \\
\text { Node }\end{array}$ & 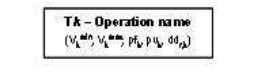 & 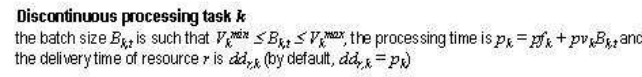 \\
\hline $\begin{array}{l}\text { Continuous task } \\
\text { Node }\end{array}$ & 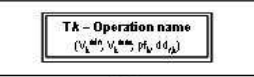 & 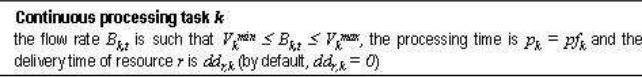 \\
\hline $\begin{array}{l}\text { Cumulative } \\
\text { resource } \\
\text { Node }\end{array}$ & & $\begin{array}{l}\text { Cumulative resource } r \\
\text { the amount } S_{z, t} \text { of stared resource } r \text { is such that } S_{z, t} \leq C_{r}^{\text {max }} \text {, the initia amount is } S Q_{r} \text {, the } \\
\text { storage policy is UIS or } N I S \text { or } F I S \text { (by default, } F I S \text { ) and the transfer policy can be } Z W \text { (by } \\
\text { defaut, none) }\end{array}$ \\
\hline $\begin{array}{c}\text { Disiuntive } \\
\text { resouroe } \\
\text { Node }\end{array}$ & & $\begin{array}{l}\text { Disjunctive resource } r \\
\text { resource which can be used by only one proces sing task at a given time }\end{array}$ \\
\hline $\begin{array}{l}\text { Stateresource } \\
\text { Node }\end{array}$ & & $\begin{array}{l}\text { State resource } r \\
\text { the amount } S_{y t} \text { is an integer indicating the actual state of the dsjunctive resouce } r \text {. It is such } \\
\text { that } S_{y t} \leq C_{\gamma}^{\text {max }} \text {, the intial marking is } S 0_{\gamma} \text { and the transfer policy can be } Z W \text { (by default, none) }\end{array}$ \\
\hline $\begin{array}{l}\text { Fixed flow } \\
\text { Aro }\end{array}$ & 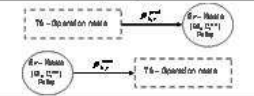 & 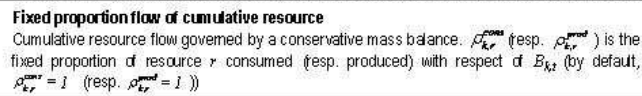 \\
\hline $\begin{array}{c}\text { Eree flow } \\
\text { Aro }\end{array}$ & (n) & 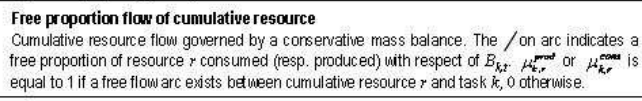 \\
\hline $\begin{array}{l}\text { Production / } \\
\text { consumption } \\
\text { Aro }\end{array}$ & 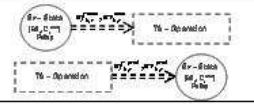 & 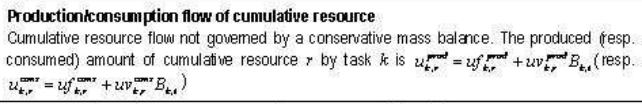 \\
\hline Use Arc & 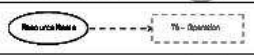 & $\begin{array}{l}\text { "Use } \text { " relationship bewween a processing task and a disjunctive resource } \\
\text { Indic ates that the disjunction resource } r \text { has the capability to perform the processing task } k \text {. }\end{array}$ \\
\hline $\begin{array}{c}\text { State transition } \\
\text { Aro }\end{array}$ & 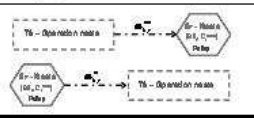 & 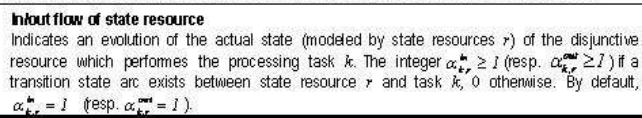 \\
\hline
\end{tabular}

list of the ERTN semantic elements $254 \times 190 \mathrm{~mm}$ (96 x $96 \mathrm{DPI})$ 


\begin{tabular}{|l|c|c|c|c|c|c|c|c|c|}
\hline Reaction & $R \mathbf{I}$ & $\boldsymbol{R 2}$ & $\boldsymbol{R 3}$ & $\boldsymbol{R 4}$ & $\boldsymbol{R 5}$ & $\boldsymbol{R} 6$ & $\boldsymbol{R} 7$ & $\boldsymbol{R} \boldsymbol{8}$ & $\boldsymbol{R} \boldsymbol{9}$ \\
\hline Reactor 1 & 2 & - & - & 3 & - & - & 1 & - & - \\
\hline Reactor 2 & 2 & - & - & 3 & - & - & 1 & - & - \\
\hline Reactor 3 & - & 2 & - & - & 2 & - & - & 3 & - \\
\hline Reactor 4 & - & - & 3 & - & - & 3 & - & - & 2 \\
\hline Reactor 5 & - & - & 3 & - & - & 3 & - & - & 2 \\
\hline
\end{tabular}

resource allocation matrix with fixed processing time (in $\mathrm{h}$ ) $254 \times 190 \mathrm{~mm}(96 \times 96 \mathrm{DPI})$ 


\begin{tabular}{|c|c|c|c|c|c|c|c|}
\hline Task & $\begin{array}{l}\text { Parameters } \\
\left(\mathrm{V}_{\mathrm{k}}^{\min }, \mathrm{V}_{\mathrm{k}}^{\max }, \mathrm{p}_{\mathrm{k}}, \mathrm{dd}_{\mathrm{k}}\right)\end{array}$ & Task & $\begin{array}{l}\text { Parameters } \\
\left(\mathrm{V}_{1}^{\min }, \mathrm{V}_{2}^{\max }, \mathrm{p}_{1}, \mathrm{dd}_{1}\right)\end{array}$ & Resource & $\begin{array}{l}\text { Parameters } \\
\left(\mathrm{R}_{0, \mathrm{r}}-\mathrm{C}_{r}^{\max }\right)\end{array}$ & Resource & $\begin{array}{l}\text { Parameters } \\
\left(R_{0, r}-C_{x}^{\max }\right)\end{array}$ \\
\hline T1 & $10,100,2,2$ & T9 & $10,80,3,3$ & A & $5000, \infty$ & G & $5000, \infty$ \\
\hline$T 2$ & $10,80,2,2$ & T10 & $10,80,3,3$ & $B$ & 0,200 & $\mathrm{H}$ & 0,200 \\
\hline T3 & $10,50,2,2$ & T11 & $10,100,1,1$ & C & 0,250 & 1 & 0,250 \\
\hline T4 & $10,80,3,3$ & T12 & $10,80,1,1$ & D & $5000, \infty$ & P1 & $0, \mathrm{P} 1$ \\
\hline T5 & $10,80,3,3$ & T13 & $10,50,3,3$ & $E$ & 0,200 & $\mathrm{P} 2$ & $0, \infty$ \\
\hline T6 & $10,100,3,3$ & T14 & $10,80,2,2$ & $F$ & 0,250 & $\mathrm{P} 3$ & $0, \infty$ \\
\hline T7 & $10,80,3,3$ & T15 & $10,80,2,2$ & LP & 0,0 & $\mathrm{HP}$ & 0,0 \\
\hline T8 & $10,50,2,2$ & & & MP & 0,0 & ELEC & 0,0 \\
\hline
\end{tabular}

utility consumption of each task (ton $/ \mathrm{kg}$ or $\mathrm{MW} / \mathrm{kg}$ ) $254 \times 190 \mathrm{~mm}(96 \times 96 \mathrm{DPI})$ 


\begin{tabular}{|l|lll|}
\hline Task & \multicolumn{1}{l}{$\begin{array}{l}\text { Parameters } \\
\left(V_{k}^{\min }, V_{k}^{\max }, p_{k}, d d_{k}\right)\end{array}$} & Resource & \multicolumn{1}{l}{$\begin{array}{l}\text { Parameters } \\
\left(\mathbf{R}_{0, \mathrm{r}}-\mathrm{C}_{\mathrm{r}}^{\max }\right)\end{array}$} \\
\hline T25 & $10,500,1,0$ & Water & $10000, \infty$ \\
\hline T26 & $10,500,1,0$ & Fuel & $10000, \infty$ \\
\hline T27 & $10,500,1,0$ & HP & 0,0 \\
\hline T28 & $10,500,1,0$ & MP & 0,0 \\
\hline T29 & $10,500,1,0$ & Int LP & 0,0 \\
\hline T25 & $10,500,1,0$ & Ehst1 & 0,0 \\
\hline T26 & $10,500,1,0$ & Water & $10000, \infty$ \\
\hline T27 & $10,500,1,0$ & Fuel & $10000, \infty$ \\
\hline
\end{tabular}

tasks and resources parameters of the site recipe of the CHP plant $254 \times 190 \mathrm{~mm}(96 \times 96$ DPI)

http://mc.manuscriptcentral.com/tprs Email: ijpr@lboro.ac.uk 